\title{
Emery-Dreifuss muscular dystrophy: the most recognizable laminopathy
}

\author{
Agnieszka Madej-Pilarczyk, Andrzej Kochański \\ Neuromuscular Unit, Mossakowski Medical Research Centre, Polish Academy of Sciences, Warsaw, Poland \\ The authors dedicate this review to Prof. Irena Hausmanowa-Petrusewicz.
}

\begin{abstract}
Emery-Dreifuss muscular dystrophy (EDMD), a rare inherited disease, is characterized clinically by humero-peroneal muscle atrophy and weakness, multijoint contractures, spine rigidity and cardiac insufficiency with conduction defects. There are at least six types of EDMD known so far, of which five have been associated with mutations in genes encoding nuclear proteins. The majority of the EDMD cases described so far are of the emerinopathy (EDMD1) kind, with a recessive $X$-linked mode of inheritance, or else laminopathy (EDMD2), with an autosomal dominant mode of inheritance. In the work described here, the authors have sought to describe the history by which EDMD came to be distinguished as a separate entity, as well as the clinical and genetic characteristics of the disease, the pathophysiology of lamin-related muscular diseases and, finally, therapeutic issues, prevention and ethical aspects.
\end{abstract}

Key words: Emery-Dreifuss muscular dystrophy, emerin, lamin A/C, laminopathy, LMNA gene.

\section{Introduction}

Laminopathies fall within a group of rare diseases connected with structural/functional defects of the proteins making up the nuclear envelope (which is composed of inner and outer nuclear membranes). This explains them also being called envelopathies. Below the inner membrane there lies the so called nuclear lamina formed by intermediate filament proteins called lamins. There are two types of lamins in human beings, with lamin $B$ encountered at all developmental stages, while lamin $A / C$ is a protein characteristic of differentiated cells in adults, which is not therefore present in the early stages of embryonic development $[14,35]$. Lamin A/C plays the role of a structural integrator in a cell nucleus, ensuring the maintenance of the latter's shape, as well as its mechanical endurance (mechanotransduction). It takes part in regulation of the cell-division cycle, through interaction with chromatin, transcription factors and associated proteins. Lamin A/C is encoded by the LMNA gene, which is composed of 12 exons and on the matrix of which two proteins are formed - lamin A and lamin C. Mature lamin A is made of prelamin $A$, which is subject to posttranslational modifications catalysed by the specific metalloproteinase FACE-1, as encoded by the ZMPSTE-24 gene [37]. Lamin A not only forms the nuclear lamin, but 
is also present in smaller amounts in another compartment of the cell nucleus - the nucleoplasm [10].

There are four phenotypic subgroups of laminopathies related to the pathology of A/C lamin, i.e. muscular and peripheral neurogenic, as well as lipodystrophies and premature ageing syndromes [44]. However, the first described envelopathy was not a laminopathy, but an emerinopathy connected with muscular pathology - Emery-Dreifuss muscular dystrophy marked later on as type 1 (EDMD 1).

\section{EDMD1 (emerinopathy): historical remarks, clinical presentation, genetic investigations}

Historically the first clinical description of the familiar muscular dystrophy with early contractures was made in 1902 by Cestan and Lejonne [13]. In 1955, Peter Emil Becker recognized a benign form of $\mathrm{X}$-linked muscular dystrophy characterized by later onset than in the Duchenne type, a slow course of disease and slightly decreased average life expectancy [3]. In 1961, Dreifuss and Hogan reported on a large four-generational family in which muscle dystrophy only occurred in 8 males. In contrast to Duchennetype muscular dystrophy, this disease was reported on by the authors by reference to its extraordinarily slow progression. Even 52-year-old and 44-year-old affected males remained ambulant, and had been able to remain active, working as a school teacher and the owner of a grocery store, respectively [15]. In 1966, Emery and Dreifuss offered a detailed characterization of the clinical features and course of the disease [16], which encompasses atrophy or weakening of muscles, mainly of the brachial and fibular groups; multiarticular contractures and rigidity of the spine; and - in further course - development of cardiomyopathy with conduction disturbances. The first symptoms of the diseases are usually seen in the first decade of life, manifesting as ankle and elbow contractures and spine rigidity. They precede muscle atrophy and weakness, which are typically visible in the $2^{\text {nd }}$ to $3^{\text {rd }}$ decades of life. It is during adolescence, as a young man grows rapidly, that contractures become more evident. Nevertheless, the progression of muscle atrophy is usually slow in the first decades of life, though tending to accelerate subsequently. In EDMD1, symptoms involving the skeletal muscles usually arise before cardiac disease, with the latter initially including sinus bradycardia, supraventricular tachyarrhythmias and paroxysmal atrial fibrillation, with atrial standstill and heart insufficiency then coming to characterize the $4^{\text {th }}$ or $5^{\text {th }}$ decades of life. Sudden death is due mainly to a complete heart block, though this is capable of being averted if a pacemaker is implanted. The full clinical picture with skeletal-muscle and cardiac involvement is to be seen in men. Female carriers never present muscle symptoms or signs, though in the $4^{\text {th }}-5^{\text {th }}$ decades of life, around $20 \%$ of them may develop overt cardiac disease, with pacemaker implantation and pharmacotherapy necessitated. It was in 1979 that the disease began being referred to as Emery-Dreifuss muscular dystrophy (EDMD, MIM 31030), while 1986 saw Thomas and co-workers succeed in mapping the gene responsible for the disease, i.e. $E M D$, which encodes the nuclear protein emerin, on the $X$ chromosome, in its q27-28 region. The maximum LOD score value of 4.29 was obtained in the case of the marker for Factor VIII. Simultaneously, genetic linkage to the Duchenne and Becker muscular dystrophy locus Xp21 was excluded, in this way offering a firm confirmation that the genetic identity of Emery-Dreifuss muscular dystrophy is separate [42]. The Warsaw Department of Neurology headed by Professor Irena Hausmanowa-Petrusewicz (1917-2015) contributed to narrowing of the Emery-Dreifuss locus to the Xq27.3-qter region and one of the 2 families analysed originated from Poland. Thanks to the highly informative contacts it proved possible to maintain with the Polish family (in which 8 males were affected), the identity of Emery-Dreifuss dystrophy could be narrowed down further [45]. The EMD gene was found to contain 6 exons. The mutations in the EMD gene first identified as responsible for EDMD1 were: $c .3 G>A$ affecting codon start in exon 1 , the nonsense c.130C $>T$ in exon 2 and c.653insTGGGC in exon 6, which influences the open reading frame and introduces a premature stop codon at 238 [5]. In the majority of EDMD1 cases, small deletions or splice-site mutations leading to a change of reading frame are observed, while remaining patients have either a nonsense/missense mutation or large deletions [http://www.umd.be/ EMD] (Fig. 1). In these circumstances, a lack of emerin can be observed in patients. Mutations are most often located in exons 1 and 2, whereas $26 \%$ of mutations are of codons 1 or $34[6,11,23]$.

\section{EDMD2 (laminopathy)}

In the 1990s, it was determined that EDMD may also be conditioned by laminopathy (EDMD 2 with an autosomal dominant trait of inheritance and 


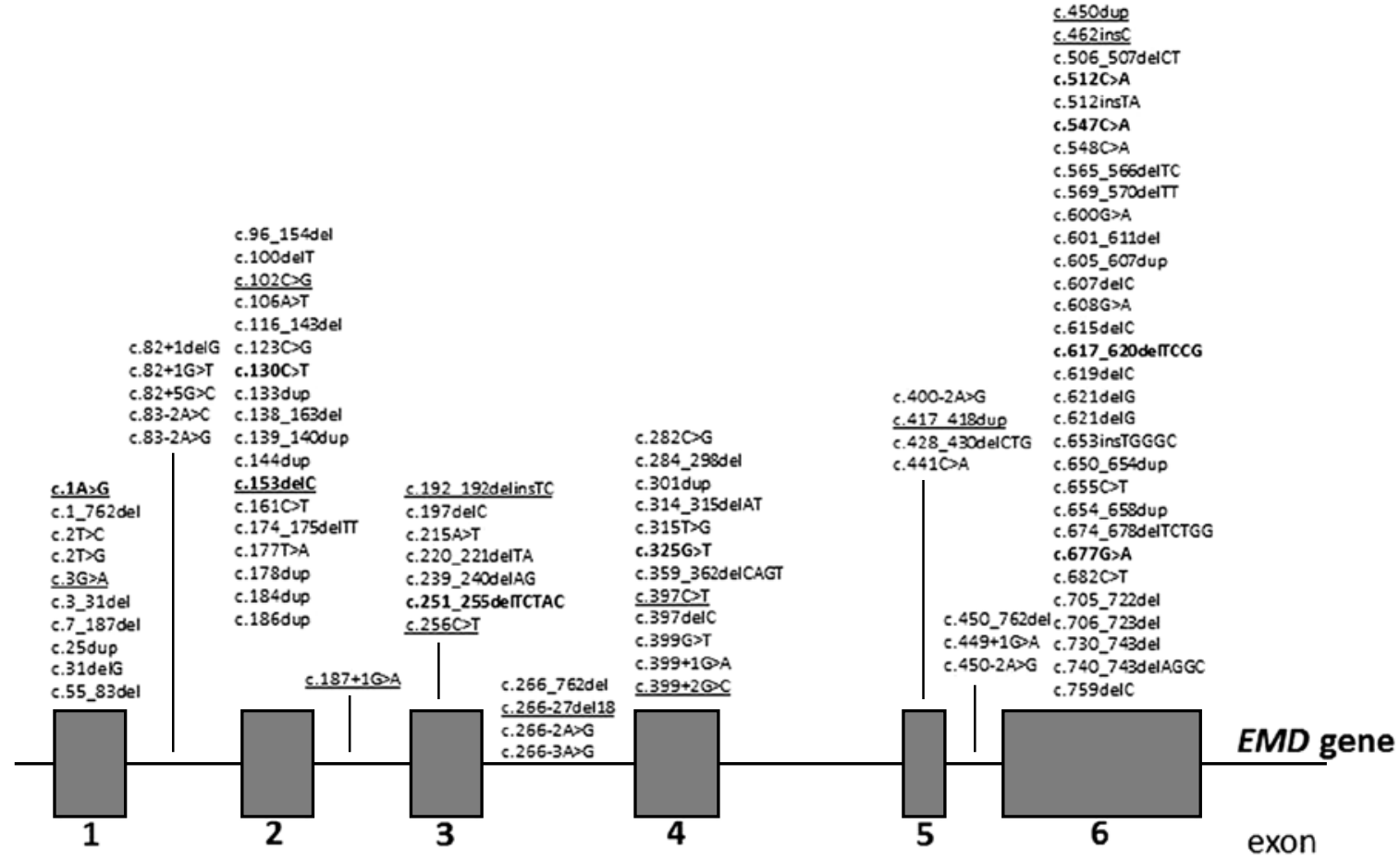

Fig. 1. Mutation spectrum in EDMD1. The most frequent mutations in the EMD gene associated with EDMD1 phenotype are marked in bold. Mutations in Polish EDMD1 patients are underlined.

Source: http://www.umd.be/EMD/

EDMD3 with a recessive one) $[7,8,33,43]$. The symptoms in skeletal muscles in EDMD2 are less stereotypical than those regarding EDMD1. Severe generalized muscle atrophy and joint contractures can occur early, leading to a loss of independent ambulance in some cases. In contrast, in others the phenotype might prove mild, with late onset and slow progression of muscle weakness and joint contractures [8]. Paraspinal ligaments are frequently affected. Weakness of respiratory muscles and chest deformity may cause respiratory failure. The cardiological component is found to be less predictable in EDMD2 than in EDMD1. Apart from conduction disturbances, systolic dysfunction of the left ventricle predominates, while the pathological process affects the ventricles more frequently, leading to dilated cardiomyopathy. Life-threatening ventricular arrhythmia is the main cause of death. As a pacemaker is not found to suffice, implantation of a cardioverter-defibrillator in primary prevention of sudden cardiac death is recommended. In 1999, Bonne et al. [7] mapped the locus for EDMD2 on chromosome 1q11-q23, which contains the LMNA gene encoding two proteins of the nuclear lamina, i.e. lamin A and lamin C. The first reported mutations in the $L M N A$ gene, as associated with EDMD 2, were: the nonsense $c .16 C>T$ in exon 1 , and the three missense mutations of $c .1357 C>T$ in exon 7, as well as C.1580G $>C$ and $1589 \mathrm{~T}>\mathrm{C}$ in exon 9. In $80 \%$ of cases of EDMD2, mutations in the LMNA gene involve heterozygous missense mutations, which result in synthesis of a mutated lamin $A / C$ with a dominant-negative toxic effect; less often they include deletions/duplications, some of which may lead to loss of function of the final protein [4]. The LMNA gene mutations in EDMD2 are disseminated randomly in exons 1-11 of the lamin A/C gene (Fig. 2). A genetic defect is most often localized in exons 1 and 6 , while recurrent mutations are seen in codons 377 and 453 [23,25]. In the majority of EDMD2 patients, it is possible to find de novo mutation in the LMNA gene [9].

\section{Other types of EDMD}

Laminopathy or emerinopathy is diagnosed in $40 \%$ of patients with the clinical picture of EDMD. A search for mutations in other genes, including those encoding proteins of the nuclear envelope that are functionally related to lamin $A / C$, allowed 


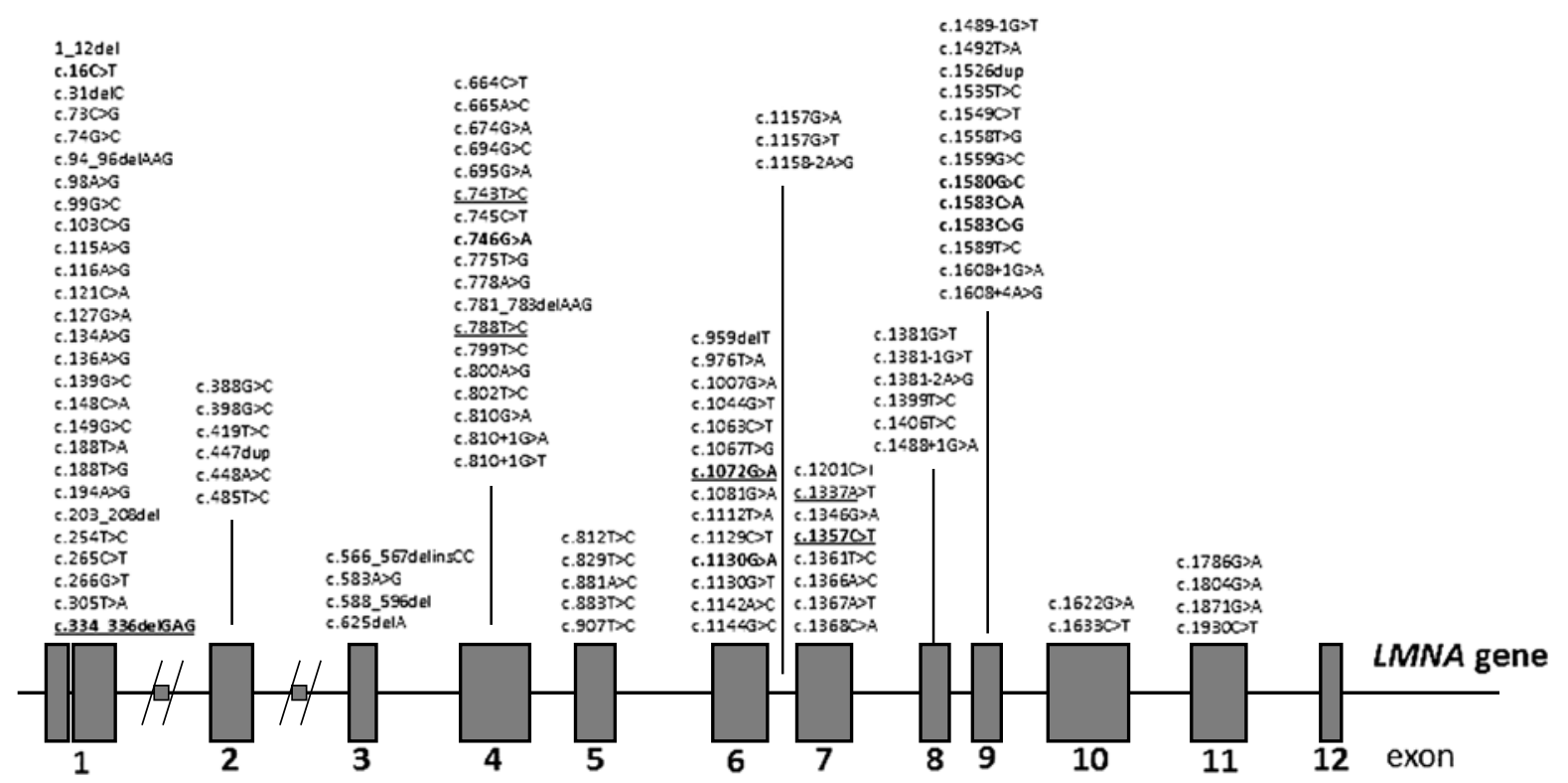

Fig. 2. Mutation spectrum in EDMD2. The most frequent mutations in the LMNA gene associated with EDMD2 phenotype are marked in bold. Mutation in Polish EDMD2 patients are underlined.

Source: http://www.umd.be/LMNA/

for the identification of SYNE 1 and SYNE 2 (the synaptic nuclear envelope protein 1(or 2) genes), encoding nesprin-1 and nesprin-2, as two genes connected with EDMD, i.e. EDMD4 and EDMD5, respectively [46]. A further candidate gene is the LAP gene encoding polypeptides connected with lamins (lamin-associated protein 2 alpha, LAP2alpha). Mutations in this gene were also reported in patients with dilated cardiomyopathy, which is clinically similar to laminopathy. In 2009, a few patients with a clinical picture resembling Emery-Dreifuss muscular dystrophy were reported with a mutation in the FHL-1 (four and a half LIM domains protein 1) gene located on the $X$ chromosome [21]. The gene is responsible for encoding one of the proteins of the cytoskeleton. A characteristic feature of EDMD6 caused by a mutation of FHL-1 is hypertrophic cardiomyopathy (as opposed to the dilated cardiomyopathy observed in the case of laminopathy), as well as deltoid hypertrophy and - often - vocal cord paresis.

\section{Pathophysiology}

A number of pathological changes can be observed in both laminopathies and emerinopathies, at both the molecular and the cellular levels. In the majority of emerinopathies, a lack or considerable reduction of emerin expression is to be observed
[26]. Some EMD mutations lead to shortening of emerin, due to premature termination of the amino-acid chain or improper exon splicing. Shortened emerin is deprived of its proper biological function and in the case of a loss of signal of nuclear localization, it may be absent from the nucleus. Ultrastructural examination of cells of skeletal, cardiac-muscle and skin fibroblasts from patients suffering from both types of EDMD has been found to show irregularly-shaped nuclei, losses of nuclear membrane and a change in the density of heterochromatin. In addition, laminopathy causes an escape of nucleoplasm beyond the boundaries of the nucleus due to losses incurred by the nuclear membrane, as well as chromatin decondensation and its detachment from nuclear lamin. In some cases pseudo-inclusions in its area are also created, while the most advanced changes may also entail fragmentation of the nucleus $[17,18,34,39]$.

Lamin A/C is expressed not only in mature myocytes, but also in stem cells of the skeletal muscles and in the satellite cells responsible for muscle regeneration [19]. Satellite cells exit the cell cycle and fuse with muscle fibre when hyperphosphorylated retinoblastoma protein $(\mathrm{pRb})$ inhibits the p21 protein responsible for continued proliferation [22,41]. In skeletal muscle, pRb binds to skeletal muscle-spe- 
cific transcriptional regulator, MyoD, induces expression of myogenesis-regulating genes and arrests the cell cycle, promoting differentiation [30]. Lamin A/C regulates the cell cycle through interaction with the pRb-MyoD complex, and via other nucleoplasmic proteins that are partners of lamin $A / C$, i.e. emerin, LAP2alpha and nesprin. Mutations in the LMNA gene responsible for muscular dystrophies cause damage and degeneration of myocytes. Simultaneous expression of mutated lamin A/C in the satellite cells responsible for repair processes hampers the regeneration process and variation of myocytes, thus contributing to the progressive development of muscular dystrophy. In muscle specimens from EDMD1/2 patients, mutations in genes encoding nuclear envelope proteins have been shown to disrupt their interactions with the pRb-MyoD complex, with the result that the process of differentiation of myoblasts into muscle fibres is impaired [2]. A lack of lamin A or emerin decreases levels of the proteins important in muscle differentiation; e.g. pRb, MyoD, desmin and M-cadherin [19]. Since LAP2alpha regulates the proliferation of stem cells in mature tissue [29], it is suggested that LAP2alpha activity in satellite muscle cells can be compromised. The LAP2alpha-lamin $A / C$ complex may be a regulator of MyoD and $\mathrm{pRb}$ in the initial step of muscle differentiation. As the inhibition of myoblast proliferation and promotion of differentiation progress, lamin A/C moves from the nucleoplasm to nuclear lamina, and the expression of LAP2alpha is seen to decrease. Introduction of mutated lamin A to nuclei in turn impairs myoblast differentiation. Mutated lamin A accumulates in the nucleoplasm and disrupts the transfer of normal lamin A to nuclear lamina (dominant-negative activity). In addition it increases interaction of LAP2alpa with wild and mutated lamin, leading to sequestration of their complexes in the nucleoplasm $[27,32]$.

Laminopathies are characterized by great intrafamilial and interfamilial variability, as regards both the phenotype generated by a given mutation (possible overlapping syndromes with other laminopathies) and the severity of the disease, from life-threatening to symptom-free carrier state [12]. Interfamilial and intrafamilial variability in patients with the same mutation may depend on phenotype modifiers: concomitant mutation in various genes - oligogenic inheritance $[20,28]$, single nucleotide polymorphisms in the mutated or another gene, var- ious expression of the protein, impaired promoter methylation, interactions with other nuclear proteins, modifying emerin/lamin A/C function and the existence of an allele with a high or low expression at the LMNA locus [36].

\section{Treatment, prevention and management of Emery-Dreifuss muscular dystrophy carriers}

There is no specific treatment for EDMD. Patients should have mild dynamic physical therapy with stretching exercises to prevent contractures. Severe contractures may be treated surgically. The best effects are obtained for ankle contractures, and the results of operation persist for longer if this is done after the adolescent growth spurt. Cardiological treatment includes implantation of a pacemaker or cardioverter-defibrillator, as well as pharmacotherapy aiming to delay heart remodeling (using ACE inhibitors), to treat arrhythmia and cardiac failure (using ACE inhibitors, diuretics and beta-blockers) and to prevent thromboembolism (using anticoagulants and antiplatelets). In patients with a preserved respiratory function and without severe muscle involvement, but who have treatment-resistant severe cardiomyopathy, heart transplantation might be considered. Patients with respiratory failure sometimes require respiratory support, especially at night.

Males diagnosed with EDMD1 and all patients with EDMD2 should be involved in regular annual cardiological screening, with this including clinical examination, ECG, echocardiography and 24-hour ECG monitoring. Obligatory female carriers of EDMD1 (i.e. daughters of men affected by it) and those with a carrier state confirmed genetically (i.e. the sisters of men affected by EDMD1, the daughters and sisters of known female carriers) should be informed about the risk of cardiomyopathy, and familiarized with the potential symptoms of cardiac insufficiency. In the case of any cardiac symptoms, the first cardiological consultation - including clinical examination, ECG and echocardiography - should be held in early adulthood, then annually; otherwise every 5 years from the age of 25 years onwards. The above guidelines are based on the recommendations of the Working Group of the National Consultant in Cardiology on cardiological supervision in Duchenne and Becker muscular dystrophy and the prevention of cardiomyopathy in female carriers of DMD/BMD [40], given that these could be taken to apply to EDMD patients as well. 
Since the penetrance of LMNA mutations, especially in relation to cardiac symptoms which might be life-threatening and even initially manifest as sudden cardiac death, is high and greater with age (being almost complete by the age of 60 ), patients with a subclinical course of the disease, including asymptomatic carriers of LMNA mutations, require careful assessment of the cardiological risk [31]. Although the muscle symptoms in EDMD usually precede heart involvement, and although the latter is seen typically in early adulthood, this sequence is generally true of EDMD1, while the clinical picture is seen to be more unpredictable in EDMD2. Some EDMD patients may have conduction disturbances or atrial arrhythmia as early as in the middle of the second decade of life [23]. Children from families affected with EDMD should therefore be observed for early signs of the disease, especially joint contractures and spine rigidity. Molecular testing should be done in the case of any abnormalities on neurological examination.

\section{Ethical issues as regards genetic testing in Emery-Dreifuss muscular atrophy}

In terms of genetic counselling, Emery-Dreifuss muscular dystrophy should be considered separately from other neuromuscular disorders limited to damage of the skeletal muscle, given the high risk of heart-rhythm disturbances and even sudden death in EDMD families. In particular, in the case of the novel EMD or LMNA mutations reported in single families, the question of penetrance remains unanswered. The marked clinical variability of EDMD, even as regards recurrent EMD/LMNA mutations, ensures that an individual risk of severe heart complications is notably hard to predict. Furthermore, in young EDMD patients, a positive result of genetic testing may result in fatalism and a deterministic attitude to further life. Indeed, a positive test result in a young patient may give rise to anxiety and distress. Moreover, molecular diagnosis of EDMD may be associated with a person feeling threatened by sudden death and thus regarding his/her own life as being of limited value. The "right not to know" confirmed by both the Council of Europe Convention on Human Rights and Biomedicine (Article 10.2) and the UNESCO Declaration on the Human Genome (Article 5c) should be considered carefully during the EDMD genetic counselling process [24]. According to some authors, in the case of a direct threat to life (also present in EDMD), the right "not to know" is of limited value [1]. Nevertheless, in young patients especially, a possible EDMD diagnosis should always entail consideration being given to the question of genetic testing and the disclosure of genetic results. In turn, clinically-healthy members of families affected by EDMD, who do not want to undergo and do not undergo genetic screening for the disease should be aware of potential cardiological symptoms, which may occur later in life and serve as the first indicator of laminopathy. In that case, prompt cardiological assessment is necessary, with genetic screening performed where the results prove to be abnormal. Similarly, the question of genetic testing for EDMD assumes special value in regard to preimplantation genetic diagnosis (PGD) and prenatal testing. In fact, in the cases of both PGD and prenatal testing for EDMD, genetic counselling deals only with the prediction of the possible phenotype, provoking ethical questions where decisions regarding embryo transfer or abortion are concerned. Additionally, due to the unknown longterm consequences of blastomere removal in PGD, the ethical dilemmas associated with EDMD-directed PGD are not to be omitted [38].

\section{Disclosure}

Authors report no conflict of interest.

\section{References}

1. Andorno R. The right not to know: an autonomy based approach. J Med Ethics 2004; 30: 435-440.

2. Bakay M, Wang Z, Melcon G, Schiltz L, Xuan J, Zhao P, Sartorelli V, Seo J, Pegoraro E, Angelini C, Shneiderman B, Escolar D, Chen YW, Winokur ST, Pachman LM, Fan C, Mandler R, Nevo Y, Gordon E, Zhu Y, Dong Y, Wang Y, Hoffman EP. Nuclear envelope dystrophies show a transcriptional fingerprint suggesting disruption of Rb-MyoD pathways in muscle regeneration. Brain 2006; 129: 996-1013.

3. Becker PE, Kiener F. Eine neue X-chromosomale Muskeldystrophie. Arch Psychiat Nervenkrank 1955; 193: 427-448.

4. Benedetti S, Menditto I, Degano M, Rodolico C, Merlini L, D’Amico A, Palmucci L, Berardinelli A, Pegoraro E, Trevisan CP, Morandi L, Moroni I, Galluzzi G, Bertini E, Toscano A, Olivè M, Bonne G, Mari F, Caldara R, Fazio R, Mammì I, Carrera P, Toniolo D, Comi G, Quattrini A, Ferrari M, Previtali SC. Phenotypic clustering of lamin A/C mutations in neuromuscular patients. Neurology 2007; 69: 1285-1292.

5. Bione S, Maestrini E, Rivella S, Mancini M, Regis S, Romeo G, Toniolo D. Identification of a novel $X$-linked gene responsible for Emery-Dreifuss muscular dystrophy. Nat Genet 1994; 8 : 323-327. 
6. Bonne G, Quijano-Roy S. Emery-Dreifuss muscular dystrophy, laminopathies, and other nuclear envelopathies. Handb Clin Neurol 2013; 113: 1367-1376.

7. Bonne G, Di Barletta MR, Varnous S, Bécane HM, Hammouda EH, Merlini L, Muntoni F, Greenberg CR, Gary F, Urtizberea JA, Duboc D, Fardeau M, Toniolo D, Schwartz K. Mutations in the gene encoding lamin A/C cause autosomal dominant Emery-Dreifuss muscular dystrophy. Nat Genet 1999; 21: 285-288.

8. Bonne G, Mercuri E, Muchir A, Urtizberea A, Bécane HM, Recan D, Merlini L, Wehnert M, Boor R, Reuner U, Vorgerd M, Wicklein EM, Eymard B, Duboc D, Penisson-Besnier I, Cuisset JM, Ferrer X, Desguerre I, Lacombe D, Bushby K, Pollitt C, Toniolo D, Fardeau M, Schwartz K, Muntoni F. Clinical and molecular genetic spectrum of autosomal dominant Emery-Dreifuss muscular dystrophy due to mutations of the lamin A/C gene. Ann Neurol 2000; 48: 170-180.

9. Bonne G, Leturcq F, Ben Yaou R. Emery-Dreifuss Muscular Dystrophy. In: Pagon RA, Adam MP, Ardinger HH, Wallace SE, Amemiya A, Bean LJH, Bird TD, Fong CT, Mefford HC, Smith RJH, Stephens K. GeneReviews ${ }^{\circledR}$ [Internet]. University of Washing ton, Seattle 1993-2015; 2004 Sep 29 [Updated 2013 Jan 17].

10. Bridger JM, Kill IR, O'Farrell M, Hutchison CJ. Internal lamin structures within G1 nuclei of human dermal fibroblasts. J Cell Sci 1993; 104: 297-306

11. Brown CA, Scharner J, Felice K, Meriggioli MN, Tarnopolsky M, Bower M, Zammit PS, Mendell JR, Ellis JA. Novel and recurrent EMD mutations in patients with Emery-Dreifuss muscular dystrophy, identify exon 2 as a mutation hot spot. J Hum Genet 2011; 56: 589-594.

12. Carboni N, Mura M, Mercuri E, Marrosu G, Manzi RC, Cocco E, Nissardi V, Isola F, Mateddu A, Solla E, Maioli MA, Oppo V, Piras R, Marini S, Lai C, Politano L, Marrosu MG. Cardiac and muscle imaging findings in a family with $X$-linked Emery-Dreifuss muscular dystrophy. Neuromuscul Disord 2012; 22: 152-158.

13. Cestan R, Lajonne NJ. Dystrophie musculaire. Iconogr Salpetriere 1902; 155: 35

14. Dauer WT, Worman HJ. The nuclear envelope as a signaling node in development and disease. Dev Cell 2009; 17: 626-638.

15. Dreifuss FE, Hogan GR. Survival in X-chromosomal muscular dystrophy. Neurology 1961; 11: 734-737.

16. Emery AE, Dreifuss FE. Unusual type of benign $\mathrm{x}$-linked muscular dystrophy. J Neurol Neurosurg Psychiatry 1966; 29: 338-342.

17. Fidziańska A, Toniolo D, Hausmanowa-Petrusewicz I. Ultrastructural abnormality of sarcolemmal nuclei in Emery-Dreifuss muscular dystrophy (EDMD). J Neurol Sci 1998; 159: 88-93.

18. Fidziańska A, Hausmanowa-Petrusewicz I. Architectural abnormalities in muscle nuclei: ultrastuctural differences between X-linked and autosomal dominant forms of EDMD. J Neurol Sci 2003; 210: 47-51.

19. Frock RL, Kudlow BA, Evans AM, Jameson SA, Hauschka SD, Kennedy BK. Lamin A/C and emerin are critical for skeletal muscle satellite cell differentiation. Genes Dev 2006; 20: 486-500.

20. Granger B, Gueneau L, Drouin-Garraud V, Pedergnana V, Gagnon F, Ben Yaou R, Tezenas du Montcel S, Bonne G. Modifier locus of the skeletal muscle involvement in Emery-Dreifuss muscular dystrophy. Hum Genet 2011; 129: 149-159.

21. Gueneau L, Bertrand AT, Jais JP, Salih MA, Stojkovic T, Wehnert M, Hoeltzenbein M, Spuler S, Saitoh S, Verschueren A, Tranchant C,
Beuvin M, Lacene E, Romero NB, Heath S, Zelenika D, Voit T, Eymard B, Ben Yaou R, Bonne G. Mutations of the FHL1 gene cause Emery-Dreifuss muscular dystrophy. Am J Hum Genet 2009; 85: 338-353.

22. Halevy O, Novitch BG, Spicer DB, Skapek SX, Rhee J, Hannon GJ, Beach D, Lassar AB. Correlation of terminal cell cycle arrest of skeletal muscle with induction of p21 by MyoD. Science 1995; 267: 1018-1021.

23. Hausmanowa-Petrusewicz I, Madej-Pilarczyk A, Marchel M, Opolski G. Emery-Dreifuss dystrophy: a 4-year follow-up on a laminopathy of special interest. Neurol Neurochir Pol 2009; 43: 415-420.

24. Kochański A, Demkow U. Next generation sequencing-ethical and social issues. In: Clinical Applications for Next Generation Sequencing. Demkow U, Ploski R (eds.). Elsevier, London 2016; pp: 295-300.

25. Madej-Pilarczyk A, Kotruchow K, Kabzinska D, Cegielska J, Kochanski A, Hausmanowa-Petrusewicz I. Emery-Dreifuss muscular dystrophy type 2 associated (?) with mild peripheral polyneuropathy. Folia Neuropathol 2015; 53: 270-274.

26. Manilal S, Recan D, Sewry CA, Hoeltzenbein M, Llense S, Leturcq F, Deburgrave N, Barbot J, Man N, Muntoni F, Wehnert M, Kaplan J, Morris GE. Mutations in Emery-Dreifuss muscular dystrophy and their effects on emerin protein expression. Hum Mol Genet 1998; 7: 855-864.

27. Markiewicz E, Venables R, Mauricio-Alvarez-Reyes, Quinlan R, Dorobek M, Hausmanowa-Petrusewicz I, Hutchison C. Increased solubility of lamins and redistribution of lamin C in X-linked Emery-Dreifuss muscular dystrophy fibroblasts. J Struct Biol 2002; 140: 241-253.

28. Muntoni F, Bonne G, Goldfarb LG, Mercuri E, Piercy RJ, Burke M, Yaou RB, Richard P, Récan D, Shatunov A, Sewry CA, Brown SC. Disease severity in dominant Emery Dreifuss is increased by mutations in both emerin and desmin proteins. Brain 2006; 129 : 1260-1268.

29. Naetar N, Korbei B, Kozlov S, Kerenyi MA, Dorner D, Kral R, Gotic I, Fuchs P, Cohen TV, Bittner R, Stewart CL, Foisner R. Loss of nucleoplasmic LAP2alpha-laminA complexes causes erythroid and epidermal progenitor hyperproliferation. Nat Cell Biol 2008; 10 : 1341-1348.

30. Novitch BG, Mulligan GJ, Jacks T, Lassar AB. Skeletal muscle cells lacking the retinoblastoma protein display defects in muscle gene expression and accumulate in $S$ and $G 2$ phases of the cell cycle. J Cell Biol 1996; 135: 441-456.

31. Pasotti M, Klersy C, Pilotto A, Marziliano N, Rapezzi C, Serio A, Mannarino S, Gambarin F, Favalli V, Grasso M, Agozzino M, Campana C, Gavazzi A, Febo O, Marini M, Landolina M, Mortara A, Piccolo G, Viganò M, Tavazzi L, Arbustini E. Long-term outcome and risk stratification in dilated cardiolaminopathies. J Am Coll Cardiol 2008; 52: 1250-1260

32. Politano L, Carboni N, Madej-Pilarczyk A, Marchel M, Nigro G, Fidziaóska A, Opolski G, Hausmanowa-Petrusewicz I. Advances in basic and clinical research in laminopathies. Acta Myol 2013; 32: $18-22$.

33. Raffaele Di Barletta M, Ricci E, Galluzzi G, Tonali P, Mora M, Morandi L, Romorini A, Voit T, Orstavik KH, Merlini L, Trevisan C, Biancalana V, Hausmanowa-Petrusewicz I, Bione S, Ricotti R, Schwartz K, Bonne G, Toniolo D. Different mutations in the LMNA gene cause autosomal dominant and autosomal reces- 
sive Emery-Dreifuss muscular dystrophy. Am J Hum Genet 2000; 66: 1407-1412.

34. Reichart B, Klafke R, Dreger C, Krüger E, Motsch I, Ewald A, Schäfer J, Reichmann H, Müller CR, Dabauvalle MC. Expression and localization of nuclear proteins in autosomal-dominant Emery-Dreifuss muscular dystrophy with LMNA R377H mutation. BMC Cell Biol 2004; 5: 12.

35. Rober RA, Weber K, Osborn M. Differential timing of nuclear lamin $A / C$ expression in the various organs of the mouse embryo and the young animal: a developmental study. Development 1989; 105: 365-378.

36. Rodríguez S, Eriksson M. Low and high expressing alleles of the LMNA gene: implications for laminopathy disease development. PLoS One 2011; 6: e25472.

37. Rusinol AE, Sinensky MS. Farnesylated lamins, progeroid syndromes and farnesyl transferase inhibitors. J Cell Sci 2006; 119: 3265-3272.

38. Sampino S, Zacchini F, Swiergiel AH, Modlinski AJ, Loi P, Ptak G. Effects of blastomere biopsy on postnatal growth and behavior in mice. Hum Reprod 2014; 29: 1875-1883.

39. Sewry CA, Brown SC, Mercuri E, Bonne G, Feng L, Camici G, Morris GE, Muntoni F. Skeletal muscle pathology in autosomal dominant Emery-Dreifuss muscular dystrophy with lamin A/C mutations. Neuropathol Appl Neurobiol 2001; 27: 281-290.

40. Sinkiewicz W, Droźdź J, Dubiel JS, Filipiak KJ, Rozentryt P, Wierzchowiecki M, Opolski G. Guidelines of National Consultant in the issue of cardiologic care of patients with Duchenne's and Becker's muscular dystrophy and cardiomyopathy prevention in woman with DMD/BMD mutations (mothers and sisters of patients with dystrophies. Kardiol Pol 2007; 65: 223-228.

41. Takahashi C, Bronson RT, Socolovsky M, Contreras B, Lee KY, Jacks T, Noda M, Kucherlapati R, Ewen ME. Rb and N-ras function together to control differentiation in the mouse. Mol Cell Biol 2003; 23: 5256-5268.

42. Thomas NS, Williams H, Elsas LJ, Hopkins LC, Sarfarazi M, Harper PS. Localisation of the gene for Emery-Dreifuss muscular dystrophy to the distal long arm of the X chromosome. J Med Genet 1986; 23: 596-598.

43. Vytopil M, Benedetti S, Ricci E, Galluzzi G, Dello Russo A, Merlini L, Boriani G, Gallina M, Morandi L, Politano L, Moggio M, Chiveri L, Hausmanova-Petrusewicz I, Ricotti R, Vohanka S, Toman J, Toniolo D. Mutation analysis of the lamin A/C gene (LMNA) among patients with different cardiomuscular phenotypes. J Med Genet 2003; 40: e132.

44. Worman HJ, Bonne G. "Laminopathies": a wide spectrum of human diseases. Exp Cell Res 2007; 313: 2121-2133.

45. Yates JR, Affara NA, Jamieson DM, Ferguson-Smith MA, Hausmanowa-Petrusewicz I, Zaremba J, Borkowska J, Johnston AW, Kelly K. Emery-Dreifuss muscular dystrophy: localisation to Xq27.3--- qter confirmed by linkage to the factor VIII gene. J Med Genet 1986; 23: 587-590.

46. Zhang Q, Bethmann C, Worth NF, Davies JD, Wasner C, Feuer A, Ragnauth CD, Yi Q Mellad JA, Warren DT, Wheeler MA, Ellis JA, Skepper JN, Vorgerd M, Schlotter-Weigel B, Weissberg PL, Roberts RG, Wehnert M, Shanahan CM. Nesprin-1 and -2 are involved in the pathogenesis of Emery-Dreifuss muscular dystrophy and are critical for nuclear envelope integrity. Hum Mol Genet 2007; 16: 2816-2833. 